\title{
Selenocarbonyl synthesis using Woollins reagent
}

\author{
Pravat Bhattacharyya and J. Derek Woollins* \\ School of Chemistry, University of St. Andrews, St. Andrews, Fife KY16 9ST, UK \\ Received 6 June 2001; accepted 21 June 2001
}

Abstract $-[\mathrm{PhP}(\mathrm{Se})(\mu-\mathrm{Se})]_{2}$ selenates secondary and tertiary amides to the corresponding selenoamides in $30-70 \%$ yields at $1300^{\circ} \mathrm{C}$
in toluene and indolizine-3-aldehydes to selenoaldehydes in $40-59 \%$ yield at $25^{\circ} \mathrm{C}$. C 2001 Published by Elsevier Science Ltd.

The utility of selenocarbonyl compounds as intermediates in heterocycle synthesis and increasing interest in the bioactivity of organoselenium compounds necessitates the development of new techniques for the introduction of selenium into organic molecules. One popular modus operandi is selenation, the exchange of a carbonyl oxygen atom for selenium. In 1997 Hill and co-workers reported the use of 'Woollins reagent', obtained from $(\mathrm{PhP})_{5}$ and elemental selenium (P:Se ratio 1:2), for converting tungsten(V) and molybdenum(V) ketenyl complexes to their selenoketenyl counterparts, ${ }^{1}$ speculating upon the identity of Woollins reagent as 2,4-bis(phenyl)-1,3-diselenadiphosphetane2,4 -diselenide $[\mathrm{PhP}(\mathrm{Se})(\mu-\mathrm{Se})]_{2}$ 1. Our subsequent crystallographic analysis ${ }^{2}$ confirmed $\mathbf{1}$ to be isostructural
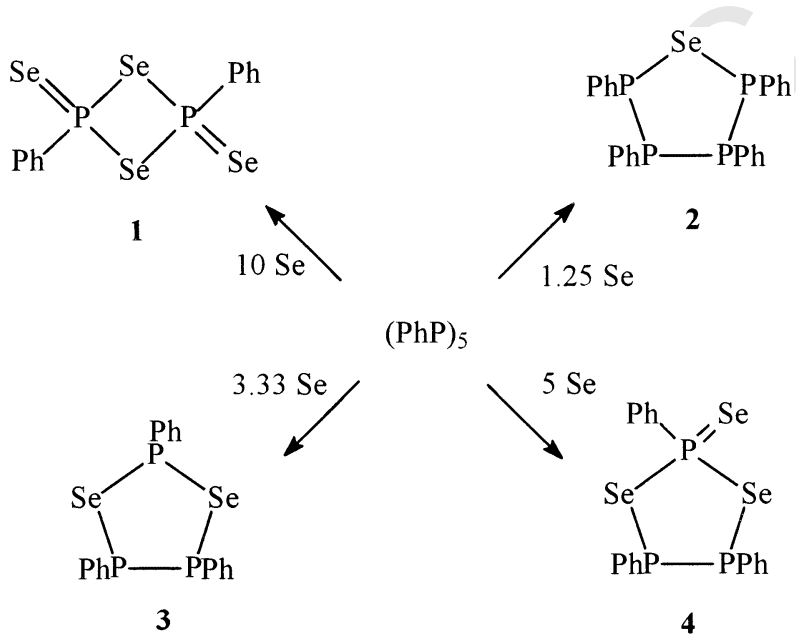

$\mathrm{PhP})_{5}$
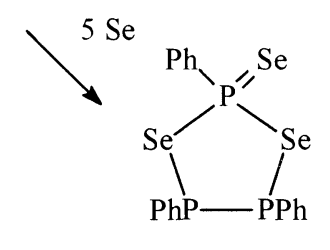

4

Figure 1. Structures of 1-4.

Keywords: selenoamide; selenoaldehyde; selenation; Woollins reagent. * Corresponding author. Tel.: +44-1334-463861; fax: +44-1334463384; e-mail: jdw3@st-and.ac.uk with the thionation agent $\left[\left(p-\mathrm{MeOC}_{6} \mathrm{H}_{4}\right) \mathrm{P}(\mathrm{S})(\mu-\mathrm{S})\right]_{2}$ (Lawesson's reagent). Although 1 has not received further attention as a selenation reagent, we have recently found this compound to be active towards a range of unsaturated organic substrates to give several unusual phosphorus containing heterocycles. ${ }^{2-4}$ We communicate here our usage of $\mathbf{1}$ for the selenation of amides and aldehydes.

Compound 1, available in 60-70\% yield upon oxidation of $(\mathrm{PhP})_{5}$ with 10 equiv. of selenium (Fig. 1), ${ }^{5-7}$ was heated together with 3 equiv. of amide in toluene at $130^{\circ} \mathrm{C}$ for the duration indicated (Table 1). Conversion is accompanied by the disappearance of insoluble $\mathbf{1}$ and

Table 1. Selenation using $\mathbf{1}^{\mathrm{a}}$

\begin{tabular}{lll}
\hline Product & Reaction time $(\mathrm{h})$ & Isolated yield $(\%)$ \\
\hline I & 1 & 72 \\
II & 2 & 70 \\
III & 7 & 30 \\
IV & 1 & 13 \\
V & 21 & 38 \\
VI & 2 & 44 \\
VII & 2 & 47 \\
VIII & 2 & 53 \\
IX & 2 & 59 \\
X & 2 & 40
\end{tabular}

a Reactions were conducted under dinitrogen, subsequent operations were performed in air. For I-VII, a mixture of $\mathbf{1}(0.2 \mathrm{mmol})$ and the substrate $(0.6 \mathrm{mmol})$ in anhydrous toluene $\left(2 \mathrm{~cm}^{3}\right)$ was heated at $130^{\circ} \mathrm{C}$. The resulting orange solution was cooled to room temperature, the solvent was removed in vacuo and the selenoamide purified by column chromatography on silica (dichloromethane). Physical data for I-VII were in accord with literature values. ${ }^{14-17}$ For the indolizine-3-aldehydes the reactions were performed at $25^{\circ} \mathrm{C}$ on a similar scale to the amides, the products VIII-X being purified by column chromatography on alumina $\left(9: 1 \mathrm{v} / \mathrm{v}\right.$ toluene/diethyl ether). ${ }^{8}$ 


$$
\begin{aligned}
& \mathrm{R}^{1}=\mathrm{Me}, \mathrm{R}^{2}=\mathrm{Me} \text { I } \\
& \mathrm{R}^{1}=\mathrm{H}, \mathrm{R}^{2}=\mathrm{Me} \text { II } \\
& \mathrm{R}^{1}=\mathrm{H}, \mathrm{R}^{2}={ }^{\mathrm{t}} \mathrm{Bu} \text { III } \\
& \mathrm{R}^{1}=\mathrm{R}^{2}=\mathrm{H} \text { IV }
\end{aligned}
$$<smiles>[Se]=C1CCCCCN1</smiles>

VI<smiles>CCNC(=S)NCC</smiles>

VII<smiles>[R][R]([R])[R]([R])[R]([R])[R]([R])[R]</smiles>

Figure 2. Selenocarbonyl products formed using 1.

precipitation of minor quantities of selenium; while $\mathbf{1}$ is appreciably more soluble in pyridine than toluene at elevated temperatures, no enhancements in yield are noted when this solvent is used. Chromatographic purification of I-VII (Fig. 2) on silica removed all phosphorus(V) by-products, characterisation being performed using ${ }^{1} \mathrm{H}$ and ${ }^{13} \mathrm{C}\left\{{ }^{1} \mathrm{H}\right\}$ NMR, IR and mass spectroscopies. The $72 \%$ yield of $\mathrm{PhC}(\mathrm{Se}) \mathrm{NMe}_{2}$ from $\mathrm{PhC}(\mathrm{O}) \mathrm{NMe}_{2}$ compares favourably with the selenation of $3-\mathrm{CH}_{3} \mathrm{C}_{6} \mathrm{H}_{4} \mathrm{C}(\mathrm{O}) \mathrm{NEt}_{2}$ by $\mathrm{PhP}(\mathrm{Se}) \mathrm{Cl}_{2}(61 \%$ yield after $5 \mathrm{~h}$ at $\left.95-100^{\circ} \mathrm{C}\right)^{8}$ and the $50 \%$ yield after $220 \mathrm{~h}$ at $90^{\circ} \mathrm{C}$ using (RP) $)_{3} \mathrm{Se}_{5}\left[\mathrm{R}=2,4-{ }^{t} \mathrm{Bu}_{2}(6-\mathrm{OMe}) \mathrm{C}_{6} \mathrm{H}_{2}\right] \cdot{ }^{9}, 10$ Notably only a $38 \%$ yield of $\mathrm{PhC}(\mathrm{Se}) \mathrm{NMe}_{2}$ using 1 is obtained after $1 \mathrm{~h}$ when selenation is carried out in pyridine. Secondary amides are readily converted to selenoamides by $\mathbf{1}$; in our hands neither $\mathrm{PhC}(\mathrm{O}) \mathrm{NHMe}$ nor \&-caprolactam were selenated satisfactorily using $\mathrm{PhP}(\mathrm{Se}) \mathrm{Cl}_{2}$, transformations which 1 effects in 70 and $44 \%$ yields, respectively. The slow conversion for $\mathrm{PhC}(\mathrm{O}) \mathrm{NH}^{t} \mathrm{Bu}$ reflects retardation due to the bulky ${ }^{t} \mathrm{Bu}$ substituent. Tetramethyloxamide is converted to the selenoxamide $\mathrm{Me}_{2} \mathrm{NC}(\mathrm{Se}) \mathrm{C}(\mathrm{O}) \mathrm{NMe}_{2}$ in $38 \%$ yield after $21 \mathrm{~h}$, with minor quantities (typically $2-3 \%$ ) of the diselenoxamide formed. While $N, N^{\prime}$-diethylurea is converted to $(\mathrm{EtNH})_{2} \mathrm{CSe}$ in moderate yield, $N, N^{\prime}$-diphenylurea does not give $(\mathrm{PhNH})_{2} \mathrm{CSe}$ but an (as yet) uncharacterised phosphorus compound $\left(\delta_{\mathrm{P}} 47.0,{ }^{1} J_{\mathrm{PSe}}\right.$ $853 \mathrm{~Hz}$ ). 1 also converts indolizine-3-aldehydes to the selenoaldehydes VIII-X at $25^{\circ} \mathrm{C}$ in yields of $40-59 \%$ after $2 \mathrm{~h}$, cf. $62-81 \%$ after $10 \mathrm{~min}$ at room temperature using $\mathrm{PhP}(\mathrm{Se}) \mathrm{Cl}_{2}{ }^{8}$ Benzamide is reluctant to undergo selenation using 1 , yields of $\mathrm{PhC}(\mathrm{Se}) \mathrm{NH}_{2}$ struggle to reach double figures; we are unable to convert nicotinamide to pyC(Se) $\mathrm{NH}_{2}$ under any conditions.

${ }^{31} \mathrm{P}\left\{{ }^{1} \mathrm{H}\right\}$ NMR of a crude mixture from the selenation of $\mathrm{PhC}(\mathrm{O}) \mathrm{NMe}_{2}$ contain several sets of doublets centred at 75 and $2 \mathrm{ppm}$, indicating $\mathrm{P}=\mathrm{Se}$ and $\mathrm{P}=\mathrm{O}$ environments, respectively. The ${ }^{31} \mathrm{P}-{ }^{31} \mathrm{P}$ couplings, typically 36-50 Hz, suggest $\mathrm{P}-\mathrm{E}-\mathrm{P}(\mathrm{E}=\mathrm{O}$ or $\mathrm{Se})$ linkages, perhaps within a cyclic structure resembling the trimer $[\mathrm{RP}(\mathrm{O})(\mu-\mathrm{O})]_{3} \quad\left[\mathrm{R}=2,4-{ }^{t} \mathrm{Bu}_{2}(6-\mathrm{OMe}) \mathrm{C}_{6} \mathrm{H}_{2}\right]$ isolated by Yoshifuji in selenation reactions using (RP) ${ }_{3} \mathrm{Se}_{5} \cdot{ }^{9,10} \mathrm{We}$ also investigated the selenating capacity of other hete- rocycles available from the $(\mathrm{PhP})_{5} / \mathrm{Se}$ system, namely $(\mathrm{PhP})_{4} \mathrm{Se} 2,(\mathrm{PhP})_{3} \mathrm{Se}_{2} 3$ and $(\mathrm{PhP})_{3} \mathrm{Se}_{3} 4$ (Fig. 1), prepared by treating $(\mathrm{PhP})_{5}$ with $1.25,3.33$ or 5 equiv. of selenium in refluxing toluene. ${ }^{5,6}$ Using $\mathrm{PhC}(\mathrm{O}) \mathrm{NMe}_{2}$ as substrate and under identical conditions to $\mathbf{1}$ we found that 2 and 3 gave 5 and $19 \%$ yields, respectively, of $\mathrm{PhC}(\mathrm{Se}) \mathrm{NMe}_{2}$ after $20 \mathrm{~h}$ at $130^{\circ} \mathrm{C}$, while 4 gave $42 \%$ yield after $1 \mathrm{~h}$, underlining the importance of a $\mathrm{P}=\mathrm{Se}$ bond for high activity. For 2-4 chromatography afforded, in addition to selenoamide, a phosphorus(V) by-product $\left(\delta_{\mathrm{P}} 24.5\right)$ which is tentatively assigned to $\mathrm{PhP}(\mathrm{O})(\mathrm{OH})_{2}$, while for 2 unreacted heterocycle can be recovered. Although 2-4 exhibit some selenation capability their air sensitivity and highly unpleasant odours compared with 1 precludes their wider usage.

The stability (shelf life of several months in air, indefinitely under nitrogen), ease of preparation and handling of $\mathbf{1}$ contrasts markedly with reagents such as NaHSe, $\mathrm{H}_{2} \mathrm{Se}, \quad\left({ }^{i} \mathrm{Bu}_{2} \mathrm{Al}\right)_{2} \mathrm{Se}, \quad\left(\mathrm{Me}_{3} \mathrm{Si}\right)_{2} \mathrm{Se}$ and bis $(1,5$-cyclooctanediylboryl)selenide, ${ }^{11-14}$ which are either air/moisture sensitive or require fresh preparation prior to use. Additionally, substrates containing $\mathrm{NH}$ groups can be satisfactorily selenated by $\mathbf{1}$, which does not appear to be the situation for $\mathrm{PhP}(\mathrm{Se}) \mathrm{Cl}_{2}$. Facile purification of the selenocarbonyls allied to its moderate tolerance towards amine protons makes $\mathbf{1}$ stand out as a selenation reagent of great promise. We are currently investigating the latitude of the reactivity of Woollins reagent towards a range of carbonyl containing substrates.

\section{Acknowledgements}

We are grateful to the EPSRC (P.B.) for funding.

\section{References}

1. Baxter, I.; Hill, A. F.; Malget, J. M.; White, A. J. P.; Williams, D. J. J. Chem. Soc., Chem. Commun. 1997, 2049. 
2. Bhattacharyya, P.; Slawin, A. M. Z.; Woollins, J. D. J. Chem. Soc., Dalton Trans. 2001, 300.

3. Bhattacharyya, P.; Slawin, A. M. Z.; Woollins, J. D. Angew. Chem., Int. Ed. 2000, 39, 1973.

4. Bhattacharyya, P.; Slawin, A. M. Z.; Woollins, J. D. J. Organomet. Chem. 2001, 623, 116.

5. Pilkington, M. J.; Slawin, A. M. Z.; Williams, D. J.; Wood, P. T.; Woollins, J. D. Heteroatom Chem. 1990, 1, 351.

6. Fitzmaurice, J. C.; Williams, D. J.; Wood, P. T.; Woollins, J. D. J. Chem. Soc., Chem. Commun. 1988, 741.

7. Wood, P. T.; Woollins, J. D. J. Chem. Soc., Chem. Commun. 1988, 1190.

8. Michael, J. P.; Reid, D. H.; Rose, B. G.; Speirs, R. A. J. Chem. Soc., Chem. Commun. 1988, 1494.

9. An, D. L.; Toyota, K.; Yasunami, M.; Yoshifuji, M. Chem. Lett. 1995, 199.

10. Yoshifuji, M.; Higeta, N.; An, D. L.; Toyota, K. Chem. Lett. 1998, 17.
11. Li, G. M.; Zingaro, R. A. J. Chem. Soc., Perkin Trans. 1998, 647.

12. Li, G. M.; Zingaro, R. A.; Segi, M.; Riebenspies, J. H.; Nakajima, T. Organometallics 1997, 16, 756.

13. Shimada, K.; Jin, N.; Kawaguchi, M.; Dobashi, K.; Nagano, Y.; Fujimura, M.; Kudoh, E.; Kai, T.; Saito, N.; Masuda, J.; Iwaya, M.; Fujisawa, H.; Aoyagi, S.; Takikawa, Y. Bull. Chem. Soc. Jpn. 1997, 70, 197.

14. Takikawa, Y.; Watanabe, H.; Sasaki, R.; Shimada, K. Bull. Chem. Soc. Jpn. 1994, 67, 876.

15. Jensen, K. A.; Nielsen, P. H. Acta Chem. Scand. 1966, 20, 597.

16. Rae, I. D.; Wade, M. J. Int. J. Sulfur Chem. 1976, 8, 519.

17. Selected data for $\mathrm{Me}_{2} \mathrm{NC}(\mathrm{O}) \mathrm{C}(\mathrm{Se}) \mathrm{NMe}_{2}: \delta_{\mathrm{H}}\left(\mathrm{CDCl}_{3}\right.$, $300.0 \mathrm{MHz}): 3.45(\mathrm{~s}, 3 \mathrm{H}), 3.15(\mathrm{~s}, 3 \mathrm{H}), 3.00(\mathrm{~s}, 3 \mathrm{H})$, $2.95(\mathrm{~s}, 3 \mathrm{H}) . \delta_{\mathrm{C}}(75.3 \mathrm{MHz}): 197.9(C=\mathrm{Se}), 168.0(C=\mathrm{O})$, 44.0, 43.7, 37.9, $34.6\left(\mathrm{CH}_{3}\right)$. Found (calcd for $\mathrm{C}_{6} \mathrm{H}_{12} \mathrm{~N}_{2} \mathrm{OSe}$ ): C 35.8 (34.8), H 6.0 (5.8), N 13.4 (13.5)\%. EI: $m / z 207, M^{+}$. 